\title{
Fungal Mastoiditis in AIDS Patients: Reported Cases
}

\section{Mastoidite Fúngica em Paciente com SIDA: Relato de Caso}

\author{
Lucas Rodrigues Carenzi*, Flavia Silveira *, Gabriel Bijos Faidiga *, Tassiana do Lago*, \\ Camila Carrara Yassuda*, Eduardo Tanaka Massuda **, Miguel Angelo Hyppolito**.
}

* Resident Doctor.

** Doctor. Professor.

Institution: Department of Otorhinolaryngology, Ophthalmology and Head and Neck Surgery at the Clinical Hospital of Ribeirão Preto of University of São Paulo's Medical School.

Ribeirão Preto / SP - Brazil.

Mailing address: Lucas Rodrigues Carenzi - Avenida Bandeirantes, 3900 - Hospital das Clínicas 12º Andar - Campus Universitário da USP -Monte Alegre - Ribeirão Preto / SP - Brazil - ZIP Code: 14049-900 - Telephone: (+55 16) 3602-2321 - Email: lucas_carenzi@yahoo.com.br

Article received on August 10, 2009. Article approved on October 23, 2009.

\section{SUMMARY}

Introduction:

Fungal mastoidits by Aspergillus fumigates predominantly occurs in immunosuppressed patients. Diagnosis is usually hard and disease is potentially fatal. Treatment is comprised of antifungal therapy, surgical debridement and immunosuppression correction.

Case Report: This article reports a case of fungal mastoiditis in a patient with acquired immunodeficiency syndrome (AIDS). The treatment performed was that of surgery associated with antifungal therapy. The patient's facial nerve was not affected, what does not exclude potentially fatal complications of mastoiditis.

Keywords: acquired immunodeficiency syndrome, mastoiditis, Aspergillus fumigatus.

\section{RESUMO}

Introdução:

Relato do Caso:

Palavras-chave:
Mastoidite fúngica por Aspergillusfumigatusocorre predominantemente em pacientes imunossuprimidos. O diagnóstico geralmente é difícil e a doença é potencialmente fatal. O tratamento consiste em terapia antifúngica, desbridamento cirúrgico e correção da imunossupressão.

Este artigo trata-se de um relato de um caso de mastoidite fúngica em um paciente com síndrome da imunodeficiência adquirida (SIDA). O tratamento realizado foi o cirúrgico associado à terapia antifúngica. O nervo facial deste paciente não estava afetado, o que não exclui complicações potencialmente fatais da mastoidite.

síndrome de imunodeficiência adquirida, mastoidite, Aspergillus fumigatus. 


\section{INTRODUCTION}

The infection by aspergillus has been associated with rhinosinusitis and invasive otitis externa $(1,2)$. Although infections by aspergillus in otorhinolaryngology are somewhat frequently reported, mastoiditis by this agent occurs very rarely $(3,4)$. Most patients with infection by aspergillus are not immunocompromised by primary diseases or derived from a treatment for other comorbidities (leukemia, diabetes, transplants). This reported case is related to an immunosuppressed patient because of AIDS, what evolved with mastoiditis by aspergillus. Few cases are known about immunocompetent patients showing infection by aspergillus $(5,6)$.

\section{Case Report}

A 33-year-old man, with no previous history of otorhinolaryngological problems, diagnosed of AIDS C3 for years, interned in the infirmary of infectious diseases of HCRP-USP, was submitted to our emergency room because of otalgia and left hypoacusia two months ago, with greenish ipsilateral otorhea for 20 days, in a small quantity, with no fever and who did not feel better after the first treatment taken, in another service, with azithromycin. The patient did not show any nasal or oral symptoms. When physical examination was made, he was thinner, discolored and afebrile. At otoscopy, a pustule was found in the posterior wall of the left external auditory canal (EAC), with a tympanic membrane (TM) retracted and hypervascularized with a liquid in the middle ear (MO). Absence of pre- or retroauricular inflammatory signs and facial palsy. To the right, a slight TM opacity was observed. Oroscopy, anterior and posterior rhinoscopy, indirect laryngoscopy and pulmonary ausculatation examinations remained unchanged. Pure-tone threshold audiometry showed a conductive loss to the left with an air-bone $20 \mathrm{~dB}$ gap in all the frequencies (250 to $8000 \mathrm{~Hz}$ ), and an immitance audiometry clearly showed a B-type curve on this side. The clinical diagnosis was secretory otitis media (SOM) and EAC pustule on the left, and the treatment started by orally administering cephalexin at a dosis of $2.0 \mathrm{~g} /$ day after draining the pustule.

No improvement was observed in both the symptomatology and the clinical examination after 4 days of treatment, so a choice was made to replace the antibiotics (ATB) for the oral administration of amoxicillin-clavulanic acid (at a dosis of $1.5 \mathrm{~g}$ and $375 \mathrm{mg} /$ day).

After five days with amoxicillin-clavulanic acid, no improvement was observed in the exam. We therefore decided to perform paracentesis of the left TM, with an

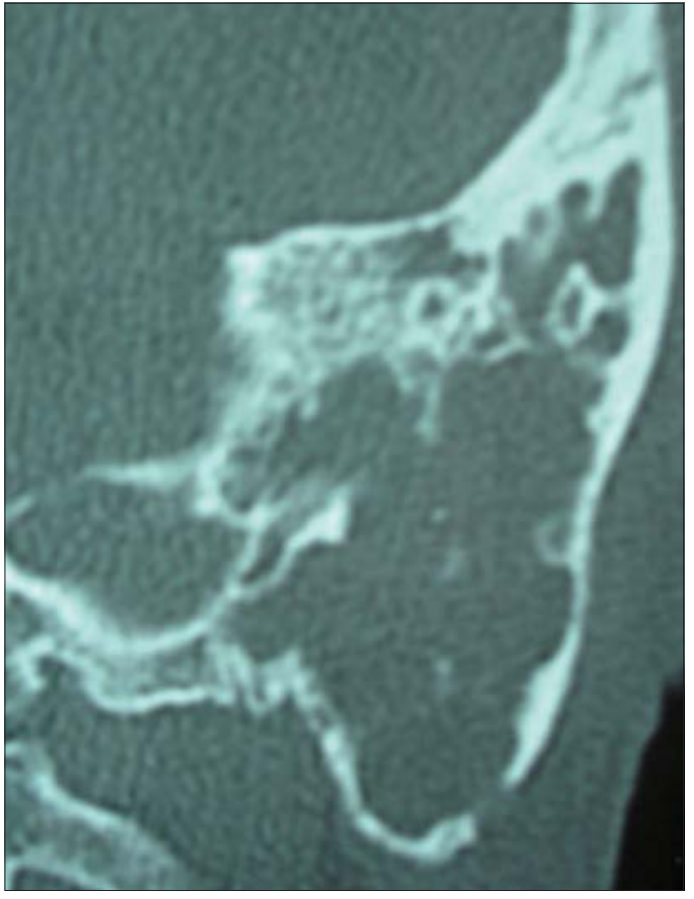

Figure 1. CT of temporal bones in coronal plan, clearly showing a density velamentum of soft parts, engaging in left mastoid cells that appear to be eroded besides the erosion occurred in the temporal bone cortex.

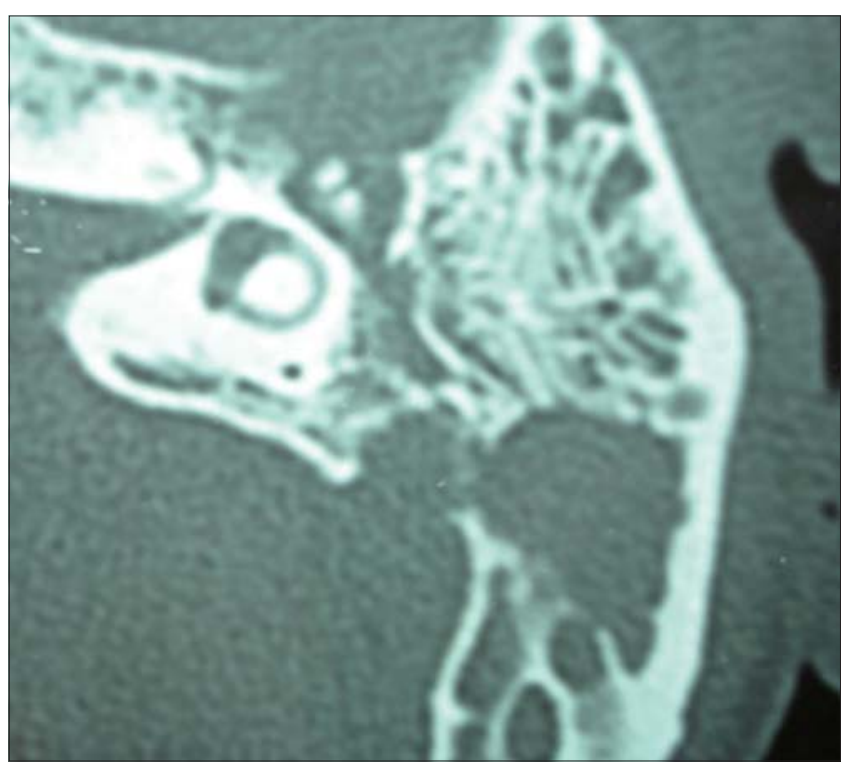

Figure 2. CT of temporal bones in axial plane, clearly showing a density velamentum of soft parts, engaging in the antrum of the left mastoid in attic area, endangering the ossicular chain, with bone erosion protruding the posterior cranial fossa.

extrusion of hyaline secretion and blood and a diagnostic supplementation with image examinations - computed tomography (CT) of temporal bones, where bone destruction on the left mastoid was evident, besides a 
velamentum throughout the ipsilateral middle ear (Figures 1 and 2).

A treatment with ceftriaxone was started intravenously at a dosis of $4 \mathrm{~g}$ /day and with a surgical intervention (simple left mastoidectomy). Findings showed a greenish-yellow secretion all over the mastoid, besides severe bone erosion and a huge antrum widening. On that occasion, materials were submitted to anatomopathological (AP) and microbiologic (cultures) examinations, whose results showed hyphas in secretion and a growth of Aspergillus fumigatus (Figure 3), respectively. It was then decided to suspend ceftriaxone and start with Amphotericin $B$ intravenously at a dosis of $1.5 \mathrm{mg} / \mathrm{kg} /$ day.

The patient developed post-surgically by showing an improvement in otalgy, but not in hypoacusia. Otoscopy presented a full TM, with a minor hyperemia and with no liquid level in the middle ear. Dehiscence in the postsurgical wound happened in the $7^{\text {th }}$ post-surgical day, with no peripheral facial palsy or mastoiditis sign, requiring daily curatives and sutures, and it succeeded when it was closed.

Afterwards, the patient developed nosocomial pneumonia and acute renal insufficiency, his clinical records were worsened by septic shock and died 51 days after surgery.

\section{DisCusSION}

Aspergillus fumigatus is a saprophyte fungus found in dust and water. Inhaling spores (conidium) causes an infection of facial sinuses and lungs, subsequently spreading to other places. Dissemination can occur hematogenically and continually to such organs as liver, kidneys and brain.

Firstly, aspergillus infection was only known in facial sinuses (7,8) until Hall and FarRior (3) (1993) included the temporal bone as an infection place. Classification includes three forms: non-invasive (responds to a simple removal), invasive (characterized by bone invasion, granulomatous response and fibrosis, occurring in immunoisuppressed patients as noticed in the case herein described), and fulminating (characterized by an invasion of the vases and a small local tissue reaction).

Sources of fungal infection for the temporal bones are meninges, hematogenic via, tympanogenic via and nasopharynx (9), and the three last ones are the most common. Reports of facial nerve involvement are found, and fungal mastoiditis must be a part of the differentiated diagnosis when this type of symptom is present. Our concern about the case described herein is the absence of facial palsy in this patient with fungal mastoiditis.

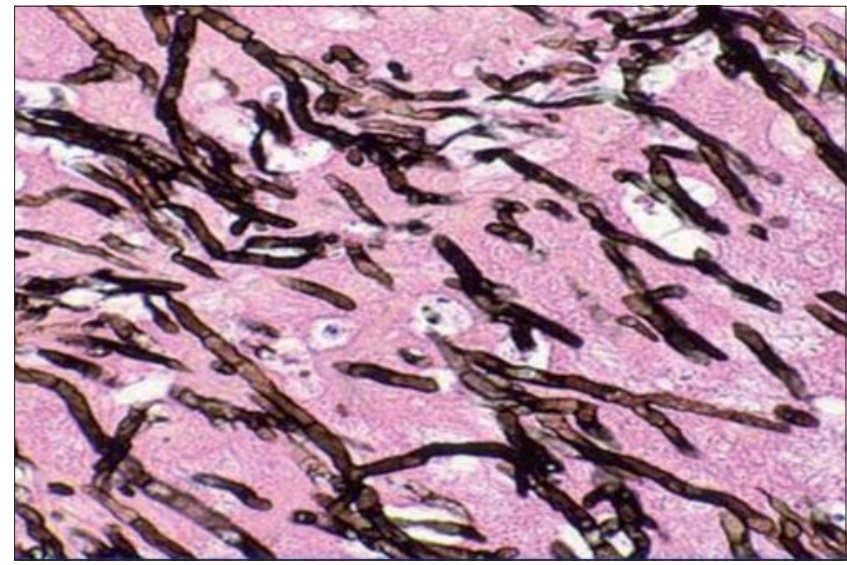

Figure 3. Anatomopathological study of silver-colored secretion, showing hyphas compatible with Aspergillus fumigatus.

This case exemplifies the difficulty to diagnose mastoiditis in immunosuppressed patients, since the symptoms and signs are less profuse because of the primary disease. TC, blood cultures and tissue biopsy (such as MO mucosa by drilling TM) can make the diagnosis easier, but they do not always confirm it. In this case, what seemed to be a SOM regarding the physical examination actually hid a chronic mastoiditis caused by the fungus, what is not usual in an adult patient, and delaying to diagnose can lead to delaying the best therapeutics.

Taking into consideration the presence of bone lysis and the patient'simmunosuppressive condition, characterizing an invasive form of the disease, the drug chosen after the treatment was amphotericin $\mathrm{B}$ for having a good performance in fungal infections by aspergillus. Amphotericin B is a polyene antifungal associated with ergosterol, causing lysisrelated cellular death, and its systemic and long-lasting utilization must be considered in situations of invasive or fulminating fungal infections in otorhinolaryngology.

\section{FinAl Commentaries}

Fungal mastoidits is a disease mainly found in immunosuppressed patients, which is hard to diagnose and must be aggressively treated because of its invasive and fulminating potential, significantly increasing the death ratio of the disease.

This report warns about the importance of actively researching the mastoid disease in immunosuppressed patients with otological complaints, since the signals and symptoms are rather profuse, what causes the diagnosis and early and effective treatment to be delayed for this particular group of patients. 


\section{BIBLIOGRAPHICAL REFERENCES}

1. Adams N F Jr. Infections involving the ethmoid, maxillary and sphenoid sinus and the orbit due to Aspergillus fumigatus. Arch Surg. 1923, 26:999-1009.

2. Petrak R M, Pottage J C. Levin S, Invasive external otitis caused by Aspergillus fumigatus in an immunocompromised patient. J Infect Dis. 1985, 151:196.

3. Hall P J, Farrior J B, Aspergillus mastoiditis. Otolaryngol Head Neck Surg. 1993, 108:167-170.

4. Teh W, Matti B S, Marisiddaiah H, Minamoto G Y, Aspergillus sinusitis in patients with AIDS: report of three cases and review. Clin Infect Dis. 1995, 21:529-535.
5. Cunningham M, Yu V L, Turner J, Curtin H, Necrotizing otitis externa due to Aspergillus in an immunocompetent patient. Arch Otolaryngol Head Neck Surg. 1988, 114:554556.

6. Bryce G E, Phillips P, Lepawsky M, Gribble MJ, Invasive Aspergillus tympanomastoiditis in an immunocompetent patient. J Otolaryngol. 1997, 26:266-269.

7. Hora J F. Primary aspergillosis of the paranasal sinuses and associated areas. Laryngoscope. 1965, 75:768-773.

8. McGill TJ. Mycotic infection of the temporal bone. Arch Otolaryngol. 1978, 104:140-144. 